\title{
Chronic autoimmune thrombocytopenic purpura associated with haemophilia A
}

\author{
Michael W. Mulholland \\ M.D.
}

\author{
J. ROGER EDSON \\ M.D.
}

\author{
JOHN P. DELANEY \\ M.D., Ph.D. \\ Department of Surgery and Coagulation Lab, University of Minnesota Hospitals, \\ Minneapolis, Minnesota, USA
}

\begin{abstract}
Summary
Two patients with haemophilia A developed chronic autoimmune thrombocytopenic purpura. Because of the increased risk of haemorrhage, splenectomy was recommended. Successful operative management included daily infusions of missing clotting factors with monitoring of blood levels in the postoperative period.
\end{abstract}

\section{Introduction}

We wish to report two cases of chronic autoimmune thrombocytopenic purpura associated with haemophilia $A$ that were successfully treated by splenectomy.

\section{Case Reports}

\section{Case 1}

A 31-year-old white male was hospitalized in April 1980 with haemophilia A and autoimmune thrombocytopenic purpura. The diagnosis of haemophilia $A$ (Factor VIII deficiency) had been made in infancy, when Factor VIII levels were found to be less than $5 \%$ of control. There was no family history of haemophilia. The patient had experienced numerous haemorrhagic complications, and was hospitalized on many occasions for the more severe episodes. He suffered a central nervous system haemorrhage in 1978, localized to the left cerebellopontine angle. Prophylaxis consisted of Factor VIII concentrate, 2000-3000 units once or twice per week on an outpatient basis.

Eighteen months before the present admission, a diagnosis of chronic active hepatitis was made, based on abnormal liver function tests and percutaneous liver biopsy. The initial treatment was prednisone (20 $\mathrm{mg}$ per day) and azathioprine (50 $\mathrm{mg}$ per day).
Four months before admission a platelet count of $39 \times 10^{9} /$ litre was noted. Azathioprine was discontinued and the dosage of prednisone was increased from $20 \mathrm{mg}$ to $40 \mathrm{mg}$ per day. Two weeks later the platelet count had fallen to $30 \times 10^{\circ} /$ litre and the prednisone dosage was further increased to $80 \mathrm{mg}$ per day.

The platelet count continued to fall and 4 weeks before admission was $20 \times 10^{9} /$ litre. Bone marrow biopsy showed increased numbers of normal appearing platelets and megakaryocytes. Anti-platelet antibodies were identified by means of the staphylococcal protein A test. During the following 6 weeks platelet counts varied from 20 to $40 \times 10^{9} /$ litre. There was no: response to the infusion of vincristine-loaded platelets (three doses of $2 \mathrm{mg}$ at 2 week intervals).

Because of the heightened potential for haemorrhage with the combination of haemophilia $A$ and thrombocytopenia, splenectomy was recommended.

At the time of admission the patient was obese, but looked well. The spleen was not palpable. The platelet count on admission was $45 \times 10^{9} /$ litre. Factor VIII levels were less than $1 \%$ of normal. Partial thromboplastin time (PTT) was $144.5 \mathrm{sec}$. Factor VIII antibodies were not detectable.

Pre-operatively the patient received 6000 units of Factor VIII concentrate and 20 units of cryoprecipitate. Immediately following this transfusion, Factor VIII levels were $97 \%$ of normal; PTT was $65.6 \mathrm{sec}$. Splenectomy was then performed with an operative blood loss of $1000 \mathrm{ml}$. Postoperatively the patient received daily transfusions of Factor VIII concentrate in doses sufficient to maintain levels above $80 \%$ of normal. This required 2000 units every $8 \mathrm{hr}$ on the first postoperative day, 1500 units every $6 \mathrm{hr}$ for postoperative days 2 and 3, and 1500 units every $8 \mathrm{hr}$ for postoperative days 4 to 12 . He was discharged to home on the 12th postoperative day and continued to receive 2000 units every $12 \mathrm{hr}$ as an out-patient for an additional 2 weeks. 
Postoperatively platelet counts rose to stable levels of approximately $300 \times 10^{9} /$ litre. During the next year of follow-up, these levels were sustained. There were no significant bleeding episodes.

\section{Case 2}

A 16-year-old white male was admitted for elective splenectomy with diagnosis of haemophilia A and autoimmune thrombocytopenic purpura in July 1981.

The patient had been diagnosed at age 4 months as having Factor VIII deficiency (less than 5\% of control). There was no family history of haemophilia. During the ensuing years he experienced multiple episodes of haemarthrosis and soft tissue haemorrhage. The patient was treated as an out-patient with Factor VIII concentrate, 1000 units every other day. Seven months before admission, a platelet count of $91 \times 10^{9} /$ litre was noted. The patient failed follow-up appointments for 6 months. One month before admission, the platelet count was $30 \times 10^{9} /$ litre. Bone marrow biopsy showed increased numbers of megakaryocytes consistent with peripheral destruction. Antiplatelet antibody titres were negative (staphylococcal protein A test). The diagnosis of idiopathic thrombocytopenic purpura was made.

Prednisone (75 mg per day) was started and the platelet count rose to $135 \times 10^{9} /$ litre but fell promptly with any attempt to taper the dosage. Temporary discontinuation of Factor VIII transfusions did not influence platelet counts. Splenectomy was advised after a month trial of steroids, because of the risk of bleeding with combined haemophilia and thrombocytopenia.

On admission the patient was a fit-looking young male. Splenomegaly was not present. The platelet count was $132 \times 10^{9} /$ litre. Factor VIII levels were $4 \%$ of normal. Partial thromboplastin time was $79.8 \mathrm{sec}$. Antiplatelet antibodies could not be detected. Antifactor VIII antibody titres were negative. Twenty-five units of cryoprecipitate and 3500 units of Factor VIII concentrate were administered. Immediately follow- ing transfusion Factor VIII levels were $145 \%$ of normal. PTT was $25.5 \mathrm{sec}$. Splenectomy was carried out with an operative blood loss of $450 \mathrm{ml}$.

Postoperatively, the patient received daily transfusions of Factor VIII concentrate, 1500 units every 8 hr. Factor VIII levels were maintained above $80 \%$ of normal for the 10 in-hospital days on this regimen. After discharge the patient received 2000 units every $12 \mathrm{hr}$ for an additional 2 weeks. There were no postoperative complications.

The platelet count rose to $600 \times 10^{9} /$ litre. In the 3 months of postoperative follow-up, the patient experienced no bleeding episodes.

\section{Discussion}

We are aware of no previous reports of chronic autoimmune thrombocytopenic purpura associated with haemophilia A. These two patients had a high potential for haemorrhagic complications with the combination of deficiency of Factor VIII and severe thrombocytopenia.

Splenectomy should be considered early in such cases, especially if improvement is not promptly obtained after 4 to 6 weeks of steroid therapy (Koller, 1980). The operative mortality of splenectomy should be less than $1 \%$ when performed with careful replacement of missing or defective haemostatic factors (Block, Evans and Zajtchuk, 1966). Daily transfusions of missing clotting factors should continue throughout the perioperative period, and may be necessary on an out-patient basis after discharge (Orringer et al., 1970).

\section{References}

Block, G.E., Evans, R. \& ZaJTchuK, R. (1966) Splenectomy for idiopathic thrombocytopenic purpura. Archives of Surgery, 92, 484.

KOLleR, C.A. (1980) Immune thrombocytopenic purpura. Medical Clinics of North America, 64, 761.

OrRINGer, E., LeWIS, M., SilverberG, J. \& RosenbaCh, L. (1970) Splenectomy in chronic idiopathic thrombocytopenic purpura. Journal of Chronic Diseases, 23, 117. 